\title{
RESEARCH
}

Open Access

\section{Translating pharmacogenetics from research to routine clinical practice - a survey of the IGNITE Network}

Kenneth D. Levy ${ }^{1}$, R. Ryanne Wu ${ }^{2,3^{*}}$, Daisuke Goto ${ }^{4}$, Michelle A. Ramos ${ }^{5}$, Victoria M. Pratt ${ }^{1}$, J. Kevin Hicks ${ }^{6}$, Ebony B. Madden ${ }^{7}$, Gillian C. Bell ${ }^{8}$, Kathryn V. Blake ${ }^{9}$, Michelle Cohen ${ }^{7}$, Benjamin Q. Duong ${ }^{10}$, James P. Franciosi ${ }^{10}$, Lori A. Orlando ${ }^{2}$, Kunal Sanghavi ${ }^{11}$ and Geoffrey S. Ginsburg ${ }^{2}$

\begin{abstract}
Background: Translating pharmacogenetic research findings that have shown clinical efficacy into sustainable, routine clinical care at the institutional level requires strong evidence of improved patient outcomes bolstered by equitable reimbursement and a sound financial analysis. Although extensive research on the clinical value of pharmacogenetics has been completed, adoption into clinical practice lags due to a lack of evidence of clinical effectiveness and limited reimbursement.

Methods: The Sustainability Working Group within the NHGRI IGNITE I Network conducted an online survey of funded and non-funded IGNITE members to determine which genes they are researching, which have been translated into clinical practice, and how tests are billed. Data from the online surveys was consolidated and analyzed with results being tabulated for key findings. Due to the limited sample size, statistical analysis was forgone and results should be considered directional in nature.

Results: Fifteen out of twenty (75\%) online survey responses were received and analyzed from IGNITE member sites delivering clinical care. Forty different genes were identified as being used for either research or clinical care. Thirty-two different genes were reported as being used clinically, an average of 6.9 genes were reported per site. Twenty-two and twenty-one genes were reported as being billed to third party payers or patients respectively. Although the survey did not ask whether sites submitting for reimbursement received payment, Medicare and Medicaid only reimburse for 6 of the 40 (15\%) genes being tested. Of the 40 genes, 18 are rated by CPIC as having A/B level of evidence with the remainder being rated as C/D or having no rating. Approximately $32 \%$ more $A / B$ rated genes were being reported clinically than non-A/B.

(Continued on next page)
\end{abstract}

\footnotetext{
* Correspondence: Ryanne.wu@duke.edu

${ }^{2}$ Center for Applied Genomics \& Precision Medicine, Duke University School

of Medicine, 304 Research Drive, Box 90141, Office 264, Durham, NC 27708,

USA

${ }^{3}$ Ambulatory Care Service, Durham, VA Medical Center, Durham, North

Carolina, USA

Full list of author information is available at the end of the article
}

(c) The Author(s). 2020 Open Access This article is licensed under a Creative Commons Attribution 4.0 International License, which permits use, sharing, adaptation, distribution and reproduction in any medium or format, as long as you give appropriate credit to the original author(s) and the source, provide a link to the Creative Commons licence, and indicate if changes were made. The images or other third party material in this article are included in the article's Creative Commons licence, unless indicated otherwise in a credit line to the material. If material is not included in the article's Creative Commons licence and your intended use is not permitted by statutory regulation or exceeds the permitted use, you will need to obtain permission directly from the copyright holder. To view a copy of this licence, visit http://creativecommons.org/licenses/by/4.0/. 


\begin{abstract}
(Continued from previous page)
Conclusion: Adoption of pharmacogenetic testing continues to lag even at sites where leading experts conduct research and have the capability to report tests clinically. Clinical research that supports CPIC A level of evidence is important for provider and payer support. Adoption of pharmacogentic testing must also be justified financially, reimbursement is one key factor, and more health economic studies are needed in order to capture the value created by preventing drug-gene adverse events, emergency room visits, and hospitalizations.
\end{abstract}

Keywords: Genomics, Reimbursement, Standard of care, Implementation science, Translational medicine, Reimbursement, Clinical validation

\section{Background}

Evidence from research efforts focused on how genomic variations influence drug response is becoming sufficiently strong to warrant translation of pharmacogenomics (PGx) into clinical practice [1]. For medications, PGx can be used as a clinical tool to help optimize drug prescribing to improve efficacy, pharmacotherapy outcomes, and mitigate drug-associated risks [2]. It is well known that translating research into routine clinical practice can take up to 17 years [3]. According to PubMed.gov, as of December 2018 there have been over 45,000 peerreviewed articles published on genomic testing and over 23,000 peer-reviewed articles published on PGx alone. As of April 2019, there were 401 clinical trials listed in clinicaltrials.gov with 54 actively recruiting subjects into studies. In 2001 upon completion of the Human Genome Project, Francis Collins, current director of the NIH stated that "by 2020 pharmacogenomics approach for predicting drug responsiveness will be standard practice for quite a number of disorders and drugs" [4]. As we approach 2020, the use of pharmacogenomic testing has yet to attain the clinical adoption envisioned by Collins. Although many pharmacogenetic tests have been technically and clinically validated [5], there continues to be numerous barriers hindering the implementation and adoption of genomic testing [6-8].

In 2013, the National Human Genome Research Institute (NHGRI) and the National Institutes of Health (NIH) initiated the Implementing Genomics in Practice (IGNITE) network, as an NIH-funded network dedicated to supporting the implementation of genomics in healthcare. The network is comprised of six research sites, affiliate members, a coordinating center, a steering committee, and working/interest groups. NHGRI and an external scientific panel provide oversight for all network activity. The research sites were tasked with finding ways to incorporate genomic information into electronic medical records and developing clinical decision support for providers across diverse healthcare settings. To that end, the IGNITE Network also disseminates the methods and best practices its members develop in order to advance the implementation of genomics in healthcare. Pharmacogenomic implementation research is a major component of the IGNITE network research focus. To further investigate the status of clinical implementation of genomic medicine by clinical researchers strongly dedicated to translating their work into clinical practice, the IGNITE Sustainability Working Group, established by the IGNITE network Steering Committee, conducted an on-line survey to assess progress towards full and sustainable clinical implementation of pharmacogenomics within clinical practice. In this article, we examine stages of pharmacogenomic evaluation and implementation across the network including the state of transition from genomic research into routine clinical care among IGNITE members, how tests are billed and/or reimbursed, and what if any financial analyses were undertaken to gain institutional level support for clinical implementation.

\section{Methods}

The IGNITE Sustainability Working Group created an online survey using REDCap [9] (Research Electronic Data Capture), hosted at Indiana University School of Medicine, and emailed the survey link to all IGNITE funded site principal investigators (PI) and affiliate members. REDCap [9] is a secure web-based application designed to support data capture for research studies, providing: 1) an intuitive interface for validated data entry; 2) audit trails for tracking data manipulation and export procedures; 3 ) automated export procedures for seamless data downloads to common statistical packages; and 4) procedures for importing data from external sources.

Prior to initiating the survey, we queried the IGNITE PIs to identify all genes that were being studied in their research laboratories and/or were being reported clinically. We identified 40 genes being tested in PI laboratories or sent out to reference laboratories (Table 1). Identified genes were grouped by Clinical Pharmacogenetics Implementation Consortium (CPIC ${ }^{\circ}$ ) prescribing action recommendations [10]. CPIC assigns grades to gene/drug pairs based on level of evidence to support "how genetic test results should be used to optimize drug therapy." CPIC level A and B gene/drug pairs have sufficient evidence for at least one prescribing action to be recommended. CPIC level C and D gene/drug pairs 
Table 1 Listing of the 40 genes identified by IGNITE member PIs and each gene's CPIC Level of Evidence. Genes with Medicare/ Medicaid reimbursement are identified with $a^{a}$

\begin{tabular}{|c|c|c|}
\hline CPIC & Gene & $\mathrm{N}$ \\
\hline $\bar{A}$ & $\begin{array}{l}\text { CYP2C19 }{ }^{\mathrm{a}} \text {, CYP2C9 }{ }^{\mathrm{a}} \text {, CYP2D6 }{ }^{\mathrm{a}} \text {, CYP3A5, CYP4F2, DPYD, G6PD, HLA A } 31 \text { 01, HLA B } 15 \text { 02 } 2^{\mathrm{b}} \text {, HLA B } 57 \text { 01, HLA B } 58 \text { 01, IFNL3, } \\
\text { SLCO1B1, TPMT, UGT1A1, VKORC1 }{ }^{\mathrm{a}}\end{array}$ & 16 \\
\hline B & CYP2B6 & 1 \\
\hline C & CYP3A4, DRD2, MTHFR & 3 \\
\hline$C / D$ & ABCB1, CYP2C8, OPRM1 & 3 \\
\hline D & HTR2A, HTR2C & 2 \\
\hline $\begin{array}{l}\text { No CPIC } \\
\text { rating }\end{array}$ & $\begin{array}{l}\text { ABCC2, ABCC3, ABCC4, CYP2C cluster rs12777823, DRD1, FAAH, GRIN2A, ITPA, NUDT15, OCT1, SLC6A4, SV2C, UGT1A9, UGT2B15, } \\
\text { UGT2B7 }\end{array}$ & 15 \\
\hline
\end{tabular}

Note: as of 4/1/19 changes to the following CPIC ratings: ABCB1 for antidepressants are level A/B, NUDT15 level A, ITPA level C/D, and SLC6A4; level B/C. ${ }^{\circ}$ Denotes genes that are reimbursed by the Centers of Medicare and Medicaid, ${ }^{b}$ Denotes gene reimbursed by Centers of Medicare and Medicaid but restricted for use in Asian populations

are not considered to have adequate evidence or actionability to have prescribing recommendations. Of the 40 genes of interest identified in this study, they spanned the range regarding level of evidence:

I. $\quad \mathrm{CPIC}^{\ominus}$ level $\mathrm{A}, \mathrm{B}$ or $\mathrm{A} / \mathrm{B},(N=17)$

II. $\mathrm{CPIC}^{\ominus}$ level $\mathrm{C}, \mathrm{D}$ or $\mathrm{C} / \mathrm{D}(N=8)$

III. No $\mathrm{CPIC}^{\bullet}$ evidence rating $(N=15)$

Our survey queried the six IGNITE funded and 18 affiliate members about their PGx activities on the 40 identified genes. Surveys were intended to help understand members' translation of PGx testing from research into clinical practice. The survey tool captured a description of the respondent (Principal Investigator, Co-Investigator, Program Manager, Other) and general characteristics of their institution (academic versus non-academic, and nonprofit or for-profit status). The survey asked how each gene was utilized, including questions on whether the gene was being used for research, reported clinically, and how billing and reimbursement was addressed. For each gene, we also asked about the institutional financial analysis requirements to transition a PGx test into clinical use and the status and barriers for those tests not implemented clinically. In addition, we asked respondents to indicate whether tests were being performed by their own laboratory (CLIA or research) or sent out to be analyzed (hospital or CLIA/CAP certified reference laboratory). The complete list of questions included in the survey can be found in Additional file 1. The survey responses were compiled and the number of genetic tests each PI reported performing was tabulated. This analysis was designed to identify the scope of PGx implementation for research and clinical use amongst IGNITE members. Due to the small number of respondent data analyzed, the results were not analyzed for statistical soundness and should be considered directional in nature.

\section{Results}

\section{Demographics of survey respondents}

Surveys were sent to the six IGNITE and 18 affiliate member PIs $(N=24)$. Of these, $18(75 \%)$ responses were received (six IGNITE PIs and 12 affiliates.) Of the responses received, we elected to exclude responses from institutions not associated with healthcare delivery $(\mathrm{N}=2)$ and healthcare institutions not performing PGx testing for research or clinical use $(N=1)$. For the remaining fifteen respondents, thirteen sites $(87 \%)$ were based within university or academic medical systems and all but one site claimed not for profit status. The fifteen included in this analysis are Cincinnati Children's Hospital Medical Center, Icahn School of Medicine at Mount Sinai, Moffitt Cancer Center, Mission Health, Nemours Children's Health System, and the Schools of Medicine at Duke University, Illinois Chicago, Indiana, Maryland, Minnesota, Pittsburgh, University of Alabama at Birmingham, University of North Carolina at Chapel Hill, and Vanderbilt University.

Each of the 15 sites included in the analysis eight PIs (53\%) were either completing testing in their own research or CLIA certified laboratory while the remaining seven sent their PGx tests out for analysis.

The survey also queried respondents about which tests they were using for their research and/or reporting clinically. All fifteen sites delivering healthcare services to patients responded that they were reporting one or more PGx test clinically.

\section{Financial justification}

PIs were asked whether their institutions required a financial evaluation be conducted prior to approving PGx testing for clinical implementation. Eight (53.3\%) reported completing financial analyses prior to clinical implementation of the PGx tests they are reporting clinically. Six (40.0\%) reported that their institution did not require a financial analysis, and one $(6.7 \%)$ did not 
respond. Five (31.3\%) had not completed the analysis for PGx tests that they plan to offer clinically, and two (12.5\%) did not respond. For the 5 sites responding that they had not completed a financial analysis, two (33.0\%) have financial analyses planned while the remaining four sites did not state the status of their intention to complete a financial justification. Additional reported requirements imposed by the respondent's institutions before clinical implementation included stakeholder(s) approval, information technology support, and a need for clinical pharmacology personnel support. Responses to an open-ended question on why testing was not currently being performed clinically included the statements: "tests not ordered on pediatric patients", "requires IT support (CDS)", "requires specialized personnel", and "still in the pre-implementation phase".

\section{Reimbursement}

Reimbursement for PGx tests is quite variable across third party payers [11]. Analyzing responses to the question of where tests were billed or how testing was reimbursed, we were unable to determine whether reimbursement was received or refused from third party payers or if patients paid for testing directly. We do know, however that 6 of the 40 tests identified by the respondents (CPIC level A level tests) are reimbursed by Medicare and Medicaid. The average number of those genetic tests per institution utilized for research was 4.5 and 5.3 for clinical reporting (Table 3). Two PGx genes, CYP2C19 and CYP2D6 accounted for an average of $25 \%$ of the tests utilized across the 15 respondents. Of the CPIC Level A/B tests reported clinically, $73 \%$ of the respondents reported billing third party payers, while only
$13 \%$ of the sites reported that they bill patients directly (Table 2). There was a very large variation in responses across the responding sites, with three sites billing third parties for all clinically reported tests, and three sites billing for less than half of the testing reported. Only two sites billed patients directly, and did so for all clinically reported genetic tests. For tests with CPIC level C/D evidence, or no rating, two of the 15 respondents indicated that they billed patients or third party payers for the tests they reported clinically (Table 2). The adoption of genetic tests for any purpose was higher for tests supported by CPIC A or B status. The adoption rate remained higher in research applications than in clinical diagnosis regardless of the level of evidence (Table 4).

Evaluating responses on the use and billing practices for PGx tests that have CMS (Medicare and Medicaid) reimbursement (6 tests); the average number of those genetic tests per institution utilized for research was 4.5 and 5.3 for clinical reporting (Table 3). Thirteen of the $15(86.7 \%)$ respondents indicated that they reported at least one PGx test clinically. In addition, 11 sites (73\%) reported billing third party payers; while only 2 sites (13\%) reported billing patients directly (Table 2). The majority of cost for PGx testing reported clinically is supported financially through other funding sources such as local, regional or national grants.

The number of CPIC A/B tests reported clinically averaged 5.53 across all 15 sites (range 1-16), and less than 1 PGx test was reported clinically among the ones with a non- $\mathrm{A} / \mathrm{B}$ rating (range $0-6$ ). As expected, PGx tests with non-A/B CPIC rating have a greater research focus. Of the 17 genes rated $A / B, 12$ remain unreimbursed by most

Table 2 CPIC Rating and IGNITE Member Sites Using pharmacogenomics testing for Research, Clinical Reporting and Billing/ Reimbursement Methods $(N=15)$

\begin{tabular}{|c|c|c|c|c|c|}
\hline \multicolumn{6}{|c|}{ CPIC A/B ( $N=17$ genes) } \\
\hline & \multicolumn{5}{|c|}{ Finances of clinical testing } \\
\hline & Used in RESEARCH & Used CLINICALLY & Billing patients & Billing $3^{\text {rd }}$ party & Other sources of funding \\
\hline Total & 11 & 15 & 2 & 11 & 8 \\
\hline$\%$ of PGx Testing sites & $73 \%$ & $100 \%$ & $13 \%$ & $73 \%$ & $53 \%$ \\
\hline \multicolumn{6}{|c|}{ CPIC C/D ( $N=8$ genes) } \\
\hline & \multicolumn{5}{|c|}{ Finances of clinical testing } \\
\hline & Used in RESEARCH & Used CLINICALLY & Billing patients & Billing $3^{\text {rd }}$ party & Other sources of funding \\
\hline Total & 7 & 2 & 1 & 1 & 3 \\
\hline$\%$ of PGx Testing sites & $47 \%$ & $13 \%$ & $7 \%$ & $7 \%$ & $20 \%$ \\
\hline \multicolumn{6}{|c|}{ No CPIC Rating ( $N=15$ genes) } \\
\hline & & & Finances & & \\
\hline & Used in RESEARCH & Used CLINICALLY & Billing patients & Billing $3^{\text {rd }}$ party & Other sources of funding \\
\hline Total & 7 & 4 & 1 & 1 & 5 \\
\hline$\%$ of PGx Testing sites & $47 \%$ & $27 \%$ & $7 \%$ & $7 \%$ & $33 \%$ \\
\hline
\end{tabular}


Table 3 Number of respondents reporting use, billing and funding for the 6 genes reimbursed by Medicare and Medicaid

\begin{tabular}{llllll}
\hline Genes & $\begin{array}{l}\text { Used in } \\
\text { Research }\end{array}$ & $\begin{array}{l}\text { Reported } \\
\text { Clinically }\end{array}$ & $\begin{array}{l}\text { Billing } 3^{\text {rd }} \\
\text { party }\end{array}$ & $\begin{array}{l}\text { Billing Patients } \\
\text { directly }\end{array}$ & $\begin{array}{l}\text { Other coverage - institutional or pilot } \\
\text { funding }\end{array}$ \\
\hline CYP2C19 & 4 & 13 & 2 & 10 & 7 \\
CYP2D6 & 8 & 8 & 1 & 4 & 5 \\
HLA B 15 02 (Asian only) & 5 & 3 & 0 & 0 & 2 \\
HLA B 57 01 & 5 & 4 & 1 & 1 & 2 \\
VKORC1 & 7 & 6 & 1 & 4 & 6 \\
CYP2C9 & 7 & 8 & 1 & 4 & 6 \\
Total & 36 & 42 & 6 & 23 & 28 \\
Range & $1-8$ & $1-8$ & $1-7$ & $0-4$ & $1-6$ \\
$\begin{array}{l}\text { Average \# genes tested per site } \\
\text { reporting }\end{array}$ & 4.5 & 5.3 & 0.8 & 2.9 & 3.5
\end{tabular}

third-party payers with 6.67 (range $0-17$ ) genes on average are being used for ongoing research. For the remaining non- $\mathrm{A} / \mathrm{B}$ rated genes the respondents identified using 2.8 CPIC C/D and 3.5 non-CPIC rated genes in their research studies (Table 4). Tests reported clinically with no reimbursement are typically funded by research grants or other funding sources.

An analysis of which of the 40 individual PGx genes are being reported clinically and how they are being billed by the 15 member sites is depicted in Table 5 . All 15 sites reported performing at least 1 PGx test clinically.

IGNITE member sites that perform larger numbers of PGx tests tend to do so across all test categories regardless of CPIC level of evidence. Only those sites clinically reporting 12 or more PGx tests included genes with lower levels of CPIC evidence in clinical reports. (This may be due to PGx panel test results being reported as individual tests when uploaded to the electronic health record).

\section{Discussion}

In this article we described a landscape analysis of primarily academic health systems associated with the IGNITE network who are conducting pharmacogenomics research and the translation of research findings into routine clinical care. Our findings summarize the current state of pharmacogenomics in early adopter settings. Fifteen of the
16 responding IGNITE members that function as academic or community care institutions have incorporated pharmacogenomics into clinical care. In addition, among the 15 respondents, all are offering tests with CPIC level of evidence A or B clinically, two are reporting level C or $\mathrm{D}$, and four are reporting CPIC non-rated PGx gene results. Many health systems are billing third party payers for CPIC level A and B tests, and most are billing third party payers for PGx tests known to be reimbursed by CMS. Interestingly, not all institutions that report PGx tests clinically were required to justify financially adding tests to the institution's clinical offering. Additionally, although sites reported billing third-party payers for select PGx tests, one cannot assume that third-party payers are reimbursing for the tests. As pointed out previously, only 6 PGx tests are currently reimbursed by CMS and many private third-party payers follow CMS reimbursement decisions [12]. Our findings suggest that when institutions are interested in adopting pharmacogenomic testing they are selective about which tests they offer, such as those with strong clinical evidence or reimbursement by third party payers. Another consideration is that reimbursement may be a more significant issue when outpatient testing is being performed. If improved outcomes can be attributed to implementing PGx testing, the total cost of care should be reduced. There have been numerous peer-reviewed

Table 4 CPIC Rating and IGNITE Member Sites' use of PGx gene testing for Research, Clinical Reporting and Billing/Reimbursement Methods (range and average number of genes tested)

\begin{tabular}{|c|c|c|c|c|c|}
\hline \multirow[t]{2}{*}{ PGx Genes } & \multirow{2}{*}{$\begin{array}{l}\text { Used in } \\
\text { Research } \\
\text { Mean per } \\
\text { site (range) }\end{array}$} & \multirow{2}{*}{$\begin{array}{l}\text { Used } \\
\text { Clinically } \\
\text { Mean per } \\
\text { site (range) }\end{array}$} & \multicolumn{3}{|l|}{ Finances } \\
\hline & & & Billing $3^{\text {rd }}$ party & Billing patients & Institutional support \\
\hline CPIC A/B $(N=17)$ & $6.67(0-17)$ & $5.53(1-16)$ & $0.93(0-13)$ & $2.66(0-13)$ & $4.13(0-16)$ \\
\hline CPIC C/D $(N=8)$ & $2.8(0-8)$ & $0.53(0-5)^{a}$ & $0.2(0-3)^{b}$ & $0.2(0-3)^{b}$ & $0.63(0-6)^{a}$ \\
\hline No CPIC rating $(N=15)$ & $3.47(3-15)$ & $0.87(0-6)$ & $0.33(0-5)^{b}$ & $0.33(0-5)^{b}$ & $1(0-6)$ \\
\hline
\end{tabular}

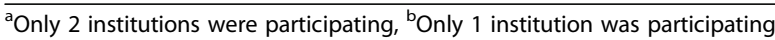


Table 5 PGx tests used in research and clinically and funding source for clinical use

\begin{tabular}{|c|c|c|c|c|c|}
\hline \multirow[t]{2}{*}{ Gene } & \multicolumn{2}{|l|}{ Type of Use } & \multicolumn{3}{|c|}{ Billing for clinical use } \\
\hline & Research Use & Clinical Use & Third parties & Patients & Institutional support \\
\hline ABCB1 & 5 & 1 & & . & 1 \\
\hline$A B C C 2$ & 3 & & . & & . \\
\hline $\mathrm{ABCC} 3$ & 2 & . & & . & \\
\hline $\mathrm{ABCC} 4$ & 2 & & . & & . \\
\hline CYP2B6 & 5 & 2 & 1 & 1 & 3 \\
\hline CYP2C cluster rs 12777823 & 6 & 3 & 1 & 1 & 3 \\
\hline CYP2C19 & 10 & 13 & 10 & 2 & 7 \\
\hline CYP2C8 & 4 & . & & . & 1 \\
\hline CYP2C9 & 7 & 8 & 4 & 1 & 6 \\
\hline CYP2D6 & 8 & 8 & 4 & 1 & 5 \\
\hline CYP3A4 & 7 & 2 & 1 & 1 & 3 \\
\hline CYP3A5 & 7 & 5 & 2 & 1 & 4 \\
\hline CYP4F2 & 5 & 3 & 2 & 1 & 4 \\
\hline DPYD & 5 & 3 & 1 & 1 & 3 \\
\hline DRD1 & 2 & . & & . & \\
\hline DRD2 & 5 & 1 & & . & 2 \\
\hline FAAH & 3 & . & & . & \\
\hline G6PD & 4 & 1 & 1 & 1 & 1 \\
\hline GRIN2A & 2 & & . & & . \\
\hline HLA A 3101 & 5 & 3 & & . & 2 \\
\hline HLA B 1502 & 5 & 3 & . & & 2 \\
\hline HLA B 5701 & 5 & 4 & 1 & 1 & 2 \\
\hline HLA B 5801 & 5 & 3 & . & & 2 \\
\hline HTR2A & 6 & 1 & 1 & 1 & 3 \\
\hline HTR2C & 5 & 1 & 1 & 1 & 3 \\
\hline IFNL3 & 4 & 3 & 1 & . & 2 \\
\hline ITPA & 3 & 1 & 1 & 1 & 1 \\
\hline MTHFR & 4 & 1 & & . & 1 \\
\hline NUDT15 & 5 & 4 & 1 & 1 & 5 \\
\hline 1-Oct & 3 & . & & . & \\
\hline OPRM1 & 6 & 1 & & . & 2 \\
\hline SLC6A4 & 6 & 1 & & . & 2 \\
\hline SLCO1B1 & 8 & 7 & 2 & 1 & 6 \\
\hline $\mathrm{SV} 2 \mathrm{C}$ & 3 & 1 & 1 & 1 & 1 \\
\hline TPMT & 5 & 7 & 6 & 1 & 4 \\
\hline UGT1A1 & 5 & 4 & 1 & 1 & 3 \\
\hline UGT1A9 & 4 & 1 & 1 & 1 & 1 \\
\hline UGT2B15 & 4 & 1 & & . & \\
\hline UGT2B7 & 4 & 1 & & . & 1 \\
\hline VKORC1 & 7 & 6 & 4 & 1 & 6 \\
\hline Average per site & 12.93 & 6.93 & 3.2 & 1.47 & 6.13 \\
\hline Range & $2-10$ & $0-13$ & $0-10$ & $0-2$ & $0-7$ \\
\hline
\end{tabular}


articles supporting this hypothesis [13-15]. One European study evaluated numerous PGx tests for cost effectiveness and found that $85 \%$ of the medications with recommendations for PGx testing demonstrated cost effectiveness [16].

Of the 40 PGx genes identified by the respondents, approximately half of the genes $(\mathrm{CPIC} A / \mathrm{B}$ genes $=17$ ) have sufficient evidence to consider implementation into clinical practice with evidence still emerging for the other genes. Since providers rely on clinical evidence to support adoption of new technology, it is expected that those genes with strong evidence for guiding drug prescribing are transitioning into clinical use more frequently. Screening and management guidelines are available for some moderate risk genes; however, these guidelines are limited in scope and continue to evolve alongside our understanding about the risks associated with these genes. Because most of the sites surveyed are implementing pharmacogenomic testing, the lower level CPIC genes may be implemented as part of their research agenda.

In addition to clinical evidence, PGx testing reimbursement by third party payers is also influenced by Food and Drug Administration (FDA) drug labeling. If, as in the case of HLAB*5701 and abacavir, the FDA recommends PGx testing [17], Medicare does offer reimbursement and many other payers may follow that lead. Recently the FDA issued an alert against the use of many pharmacogenetic tests with unapproved claims to predict patient response to specific medications [18]. The agency expressed its concern that they have not reviewed all drug-gene and variant pairs and thus, the claims by clinical laboratories may not be supported by clinical evidence. It is important to note that the FDA does not recognize CPIC's review of the evidence and assignment of levels [19].

The lack of payer coverage remains problematic in PGx testing. Most insurers regard PGx testing, especially large gene panels as not medically necessary [20]. There are a few examples where a single gene for a single indication is reimbursed [12], and there are also some payers that cover panel testing for patients diagnosed with depression or psychiatric disorders, particularly those with refractory disease. However, at present, most payers do not reimburse for PGx panel testing.

Individual organizations use a variety of methods for reimbursement of clinical testing. For inpatients, clinical testing may be reimbursed from dollars received by the diagnostic related group (DRG), which is a system that standardizes payment to hospitals and encourages cost containment initiatives related to the patient diagnosis (e.g., kidney transplant). In general, a DRG is a lumpsum payment for all medical services received during an episode of care. With institutional approval, DRG payments may cover the costs of PGx testing. For outpatient testing, a patient's insurance may be billed. If the patient does not have insurance, or third-party billing does not cover PGx testing, the patient may be billed directly. For example, one reference laboratory offers self-pay options that are tiered, based on a patient's income, with maximum charges as low as a couple hundred dollars. Direct-to-consumer genomic testing options are emerging that offer testing for hereditary disease risk and PGx [21]. As direct-to-consumer genomic testing options evolve and genotyping/sequencing costs continue to decrease, reimbursement of pharmacogenomic tests may cover the cost of testing but not provide a significant source for revenue. Financial sustainability may ultimately be driven by avoidance of poor pharmacotherapy outcomes and potentially reimbursement models for cognitive services related to interpretation and application of genomics to patient care.

Depending on the location of the laboratory, billing for PGx testing can vary. If the PGx laboratory is considered a reference laboratory (e.g., it is outside the physician/hospital practice), then the laboratory bills the institution, called institutional billing, usually under a contracted price. Third party billing or insurance billing is when an intermediary (e.g., the insurance company/ payer) handles invoicing and payment between the laboratory and the patient. Payment can be through contracted or uncontracted pricing depending upon the relationship between the laboratory and the insurance company or the laboratory and the hospital or provider. In this study, the most common method of billing is for the laboratory to invoice the institution and the institution bill the payer and/or patient. As noted, in this survey, we did not inquire whether reimbursement was received by IGNITE member sites when laboratories billed third party payers. Previous studies [8] have shown the importance of reimbursement for implementation and sustainability of genomic testing.

Our analysis of the survey data demonstrates that a little over half of the respondent's laboratories performed some sort of financial analysis to determine feasibility of implementing PGx. The survey did not explore the type of analysis, but often such analyses look at costs to perform the test of interest, estimated test volumes (or send out testing volumes), reimbursement and other factors.

It is important to acknowledge that the results reported in this study of genomic test implementation was limited to IGNITE members, thus the results may not be representative of sites not engaged in genomic research or associated with universities or large academic medical centers.

\section{Conclusion}

The practice of genomic medicine encompasses numerous current and potential future clinical uses, including 
oncology, prenatal and postnatal testing, and medication therapeutic efficacy prediction. The NIH and other governmental (US and foreign) funding agencies continue to see the potential benefit that genomic medicine offers, however, numerous barriers continue to slow the adoption of genomic testing into routine clinical practice. The IGNITE network may be categorized as an early adopter of PGx technology with principal investigators being recognized nationally and internationally and widely published on their work in genomic research and applying their research into clinical practice. Yet only a limited number of sites have translated a broad array of PGx tests into clinical practice. Moreover, for those who have, it is far from being categorized as being accepted into routine clinical care. The network has investigated the barriers to the adoption of genomic testing; the lack of clinical evidence and limited reimbursement were two of the four major barriers identified [8, 22]. Reimbursement for genomic testing, as with any new laboratory test or new diagnostic modality is critical for successful adoption and sustainability. For example, when the Blue Cross and Blue Shield Association (BCBS) formed the Technology Evaluation Center (TEC) to evaluate emerging technologies they included five main criteria for evaluating whether a technology was worthy of reimbursement. They included:

- The technology must meet regulatory guidelines

- There must be strong clinical evidence on the technologies positive impact on clinical outcomes

- The technology must provide equal or improved clinical benefits as compared to previously established alternatives

- There must be a demonstrated positive net health outcome

- The new technology must be implementable in realworld clinical settings

If any of the above criteria is not met, the technology will be considered investigational and not eligible for coverage [23]. As one might imagine, meeting the above criteria to obtain private payer reimbursement require numerous large clinical and health economic studies. To date, there are numerous clinical studies focused on PGx testing that have been evaluated by independent reviewers (CPIC, Dutch Pharmacogenetics Working Group, and the European Pharmacogenetics Implementation Consortium) with established guidelines for 20 different genes impacting 44 medications based on the strong clinical evidence demonstrated. In our study, the respondents identified 40 different genes that were either being studied in funded research or used clinically, thus widening the gap between PGx tests that are reimbursed and those that researchers believe to be clinically relevant. Despite this, the perception is that sufficient clinical evidence does not yet exist. Further work needs to be done to create longitudinal randomized clinical trials to demonstrate the long-term impact on population health that is possible with implementation of PGx testing. In addition to delivering strong clinical evidence, third party payers also strongly weigh the financial impact of adding a new technology. Further studies are needed to evaluate the health economic impact that PGx and other genomic testing have on the healthcare system. Until there are sufficient health economic studies delivering strong financial justification, PGx and other genomic testing will continue to be categorized as a boutique diagnostic and relegated to early adopter university/academic medical centers. The additional barriers identified by Obeng et al. were a lack of provider education and knowledge regarding genomic testing and how to incorporate results into current therapy regimens, and the lack of genomic test results and clinical decision support (CDS) tools being incorporated into electronic medical record systems [22]. To help close the knowledge gap, IGNITE members have developed and contributed provider genomic training materials and CDS tools that are available in the IGNITE Supporting Practice through Applications, Resources and Knowledge ("SPARK") toolbox found on the IGNITE website [24]. Researchers and health care administrators need to collaborate with the large electronic health record (EHR) companies to further integrate CDS tools related to PGx into the EHR so that clinicians are not left to order, interpret, and apply PGx results to their patients without integration and guidance from current clinical guidelines.

To encourage the adoption and reimbursement of PGx testing will require the development of national PGx testing registry to develop strong and large databases of clinical evidence, a focus on standards in PGx testing and reporting, and the expansion of costeffectiveness analysis studies to build partnerships with payers.

\section{Supplementary information}

Supplementary information accompanies this paper at https://doi.org/10. 1186/s41231-020-00057-y.

Additional file 1. (IGNITE Sustainability Survey Tool)

\section{Abbreviations}

BCBS: Blue Cross Blue Shield Association; CDS: Clinical Decision and Support; CLIA/CAP: Clinical Laboratory Improvement Amendments/College of

American Pathologists; CMS: Centers for Medicare and Medicaid Services;

CPIC: Clinical Pharmacogenetics Implementation Consortium;

DRG: Diagnostic Related Group; FDA: Food and Drug Administration;

IGNITE: Implementing Genomics in Practice; NHGRI: National Human Genome Research Institute; NIH: National Institutes of Health;

PGx: Pharmacogenetics; PI: Principal Investigator; REDCap: Research Electronic Data Capture; SPARK: Supporting Practice through Applications, Resources and Knowledge 


\section{Acknowledgements}

We gratefully acknowledge the support from the National Human Genome Research Institute and the IGNITE Network Coordinating Center at Duke University for their support in conducting this research.

\section{Authors' contributions}

$\mathrm{KL}, \mathrm{DG}$, and RW developed the analytic plan and completed the analysis. All authors listed contributed to the writing and editing of the article. All authors read and approved the final article.

\section{Funding}

This research is supported by the NIH/NHGRI IGNITE Network U01 Grant and administrative supplement to Indiana University School of Medicine 5U01HG007762-04 and 3U01HG007762-04S2.

\section{Availability of data and materials}

All data generated or analyzed during this study are available from the corresponding author on reasonable request.

\section{Ethics approval and consent to participate}

This article does not contain patient personal health information nor does it reference individual study site human research results.

\section{Consent for publication}

Not applicable.

\section{Competing interests}

Daisuke Goto is employed by Merck Sharp \& Corp. and shareholder, Merck \& Co. Inc. Vicky Pratt is the Director of the IU School of Medicine Pharmacogenomics Laboratory that also serves as a fee-for-service clinical reference laboratory. J. Kevin Hicks is a paid academic associate for Quest Diagnostics and receives funding from OneOme Inc.; all other contributing authors declare that they have no competing interests.

\section{Author details}

IIndiana University School of Medicine, Indianapolis, Indiana, USA. ${ }^{2}$ Center for Applied Genomics \& Precision Medicine, Duke University School of Medicine, 304 Research Drive, Box 90141, Office 264, Durham, NC 27708, USA. ${ }^{3}$ Ambulatory Care Service, Durham, VA Medical Center, Durham, North Carolina, USA. ${ }^{4}$ University of Maryland School of Pharmacy, Baltimore, MD, USA. ${ }^{5}$ Icahn School of Medicine at Mount Sinai, New York, NY, USA. ${ }^{6} \mathrm{H}$. Lee Moffitt Cancer Center and Research Institute, Tampa, Florida, USA. ${ }^{7}$ National Human Genome Research Institute, Bethesda, MD, USA. ${ }^{8}$ Mission Health, Fullerton Genetics Center, Ashville, North Carolina, USA. ${ }^{9}$ Nemours Children's Specialty Care, Jacksonville, Florida, USA. ${ }^{10}$ Nemours Children's Hospital, University of Central Florida College of Medicine, Orlando, Florida, USA. "'The Jackson Laboratory for Genomic Medicine, Farmington, CT, USA.

Received: 9 October 2019 Accepted: 17 March 2020 Published online: 29 April 2020

\section{References}

1. Weitzel KW, Elsey AR, Langaee TY, Burkley B, Nessl DR, Obeng AO, et al. Clinical pharmacogenetics implementation: approaches, successes, and challenges. Am J Med Genet C Semin Med Genet. 2014;166C(1):56-67.

2. Zhang G, Nebert DW. Personalized medicine: genetic risk prediction of drug response. Pharmacol Ther. 2017;175:75-90.

3. Morris ZS, Wooding S, Grant J. The answer is 17 years, what is the question: understanding time lags in translational research. J R Soc Med. 2011;104(12): 510-20.

4. Collins FS, McKusick VA. Implications of the human genome project for medical science. JAMA. 2001;285(5):540-4.

5. Relling MV, Klein TE. CPIC: clinical Pharmacogenetics implementation consortium of the pharmacogenomics research Network. Clin Pharmacol Ther. 2011;89(3):464-7.

6. Frueh FW. Regulation, reimbursement, and the long road of implementation of personalized medicine--a perspective from the United States. Value Health. 2013;16(6 Suppl):S27-31.

7. Sperber NR, Carpenter JS, Cavallari LH, La JD, RM C-DH, Denny JC, et al. Challenges and strategies for implementing genomic services in diverse settings: experiences from the Implementing GeNomics In pracTicE (IGNITE) network. BMC Med Genomics. 2017;10(1):35.

8. Levy KD, Blake K, Fletcher-Hoppe C, Franciosi J, Goto D, Hicks JK, et al. Correction: opportunities to implement a sustainable genomic medicine program: lessons learned from the IGNITE Network. Genet Med. 2018.

9. Harris PA, Taylor R, Thielke R, Payne J, Gonzalez N, Conde JG. Research electronic data capture (REDCap)--a metadata-driven methodology and workflow process for providing translational research informatics support. J Biomed Inform. 2009;42(2):377-81.

10. CPIC Prescribing Guidelines [Internet]. Available from: https://cpicpgx.org/ guidelines/.

11. Lu CY, Loomer S, Ceccarelli R, Mazor KM, Sabin J, Clayton EW, et al. Insurance Coverage Policies for Pharmacogenomic and Multi-Gene Testing for Cancer. J Pers Med. 2018;8(2):19.

12. Network I. Mapping of Pharmacogenetic Testing According to MAC [MAC locations and PGx tests reimbursed by MAC]. Available from: https://ignitegenomics.org/mac-reimbursement-map/.

13. Plothner M, Ribbentrop D, Hartman JP, Frank M. Cost-effectiveness of Pharmacogenomic and Pharmacogenetic test-guided personalized therapies: a systematic review of the approved active substances for personalized medicine in Germany. Adv Ther. 2016;33(9):1461-80.

14. Plumpton CO, Pirmohamed M, Hughes DA. Cost-effectiveness of panel tests for multiple Pharmacogenes associated with adverse drug reactions: an evaluation framework. Clin Pharmacol Ther. 2018;105:1429.

15. Alagoz O, Durham D, Kasirajan K. Cost-effectiveness of one-time genetic testing to minimize lifetime adverse drug reactions. Pharmacogenomics $」$. 2016;16(2):129-36

16. Berm EJ, Looff M, Wilffert B, Boersma C, Annemans L, Vegter S, et al. Economic Evaluations of Pharmacogenetic and Pharmacogenomic Screening Tests: A Systematic Review. Second Update of the Literature. PLoS One. 2016;11(1):e0146262.

17. FDA. HLAB*5701 and abacavir safety.

18. FDA. Medical Devices Safety.

19. U.S. FDA. Drugs@FDA: FDA-Approved Drugs. Federal Drug Administration, May 2018; 20 March 2020. https://www.accessdata.fda.gov/scripts/cder/daf/ index.cfm?event=overview.process\&varApp/No=020977.

20. Provider U. Payer's views on PGx panels.

21. Crow D. A new wave of genomics for all. Cell. 2019;177(1):5-7.

22. Owusu Obeng A, Hamadeh I, Smith M. Review of opioid Pharmacogenetics and considerations for pain management. Pharmacotherapy. 2017;37(9):1105-21.

23. Ziegler KM, Flamm CR, Aronson N. The blue cross blue shield association technology evaluation center: how we evaluate radiology technologies. J Am Coll Radiol. 2005;2(1):33-8.

24. Network I. IGNITE "SPARK" Toolbox [Available from: https:/ignite-genomics. org/spark-toolbox/). Accessed 15 Feb 2020.

\section{Publisher's Note}

Springer Nature remains neutral with regard to jurisdictional claims in published maps and institutional affiliations.
Ready to submit your research? Choose BMC and benefit from:
- fast, convenient online submission
- thorough peer review by experienced researchers in your field
- rapid publication on acceptance
- support for research data, including large and complex data types
- gold Open Access which fosters wider collaboration and increased citations
- maximum visibility for your research: over $100 \mathrm{M}$ website views per year
At BMC, research is always in progress.
Learn more biomedcentral.com/submissions 